\title{
Correction to: Effects of Parental Acceptance-Rejection on Children's Internalizing and Externalizing Behaviors: A Longitudinal, Multicultural Study
}

W. Andrew Rothenberg $\mathbb{D}^{1,2} \cdot$ Sumbleen $\mathrm{Ali}^{3,4} \cdot$ Ronald P. Rohner ${ }^{4} \cdot$ Jennifer E. Lansford ${ }^{1} \cdot$ Preston A. Britner ${ }^{4}$. Laura Di Giunta ${ }^{5} \cdot$ Kenneth A. Dodge ${ }^{1} \cdot$ Patrick S. Malone $^{1} \cdot$ Paul Oburu $^{6} \cdot$ Concetta Pastorelli $^{5} \cdot$ Ann T. Skinner $^{1}$. Emma Sorbring ${ }^{7} \cdot$ Laurence Steinberg $^{8,9} \cdot$ Sombat Tapanya $^{10} \cdot$ Liliana Maria Uribe Tirado $^{11}$.

Saengduean Yotanyamaneewong ${ }^{10} \cdot$ Liane Peña Alampay $^{12} \cdot$ Suha M. Al-Hassan $^{13} \cdot$ Dario Bacchini $^{14}$. Marc H. Bornstein ${ }^{15,16,17} \cdot$ Lei Chang ${ }^{18} \cdot$ Kirby Deater-Deckard $^{19}$

Published online: 15 November 2021

(c) Springer Science+Business Media, LLC, part of Springer Nature 2021

Correction to: Journal of Child and Family Studies https://doi.org/10.1007/s10826-021-02072-5

In this article few affiliations were incorrect: the affiliation for author Sumbleen Ali should have been. "The State
University of New York College at Oneonta, Oneonta, USA" and "University of Connecticut, Storrs, USA"; authors Ronald P. Rohner and Preston A. Britner "University of Connecticut, Storrs, USA". The original article has been corrected.

The original article can be found online at https://doi.org/10.1007/ s10826-021-02072-5.

W. Andrew Rothenberg

rothenbergdrew@gmail.com

1 Center for Child and Family Policy, Duke University, Durham, NC, USA

2 Mailman Center for Child Development, University of Miami Miller School of Medicine, Miami, FL, USA

3 The State University of New York College at Oneonta, Oneonta, NY, USA

4 University of Connecticut, Storrs, CT, USA

5 Università di Roma "La Sapienza”, Rome, Italy

6 Maseno University, Kisumu, Kenya

7 University West, Trollhättan, Sweden

8 Temple University, Philadelphia, PA, USA
9 King Abdulaziz University, Jeddah, Saudi Arabia

10 Chiang Mai University, Chiang Mai, Thailand

11 Universidad San Buenaventura, Bogotá, Colombia

12 Ateneo de Manila University, Quezon City, Philippines

13 Hashemite University, Zarqa, Jordan

14 University of Naples "Federico II", Naples, Italy

15 National Institute of Child Health and Human Development, Bethesda, MD, USA

16 UNICEF, New York, NY, USA

17 Institute for Fiscal Studies, London, United Kingdom

18 University of Macau, Macau, China

19 University of Massachusetts Amherst, Amherst, MA, USA 